Teresa Kleba Lisboa

Universidade Federal de Santa Catarina

\title{
Fluxos migratórios de mulheres para o trabalho reprodutivo: a globalização da assistência
}

\begin{abstract}
Resumo: A partir de uma experiência vivenciada como integrante do grupo que trabalhou a temátic a da migração de mulheres na Internationa le Frauen Universität (IFU) em 2000, a presento neste artigo uma discussão sobre os fluxos migratórios de mulheres que deixam os países periféric os movendo-se em direção aos países de Primeiro Mundo para trabalhar como emprega das doméstic as. Ocorre nesse processo uma verda deira globalização da assistência, formando-se inclusive cadeias entre mulheres de diferentesnações, classese etnias. As princ ipa is causas das migrações estão ligadas à luta pela sobrevivência, oportunidade de trabalho e estudo e conquista da independência em relação à opressão e à violência. Como proposta final, sugiro que, para conter os fluxos migrató rios, são necessá ria spolític as públicas que venham ao enc ontro das necessidades básicas das mulheres em seus países de origem.
\end{abstract}

Pala vras-chave: migração feminina; g lobaliza ção da assistência; eqüida de de gênero; polític as públic as para mulheres.

Copyright 2007 by Revista Estudos Feministas.

${ }^{1}$ A IFU foi um curso de especia lização com conteúdo programático de 360 horas, promovido pelo DAAD - Deutcher Akademischer Austa usc hdients, e oc orreu simultanea mente à exposição mundial EXPO 2000, em Hannover.

${ }^{2}$ Teresa Kleba LSBOA, 2003.
De 15 julho a 15 de outubro do ano 2000, ocorreu na Alemanha a IFU - Internationale Frauen Universität (Universidade Internacional de Mulheres), ${ }^{1}$ que reuniu mil mulheres de 115 nações para socializa rem experiências, participa rem de projetos de pesquisa ela borando estudos, rela tóriose doc umentos so bre seis área stemátic as: 1. Corpo - experiências polític as e concepções; 2 . Cidades-gênero e cidades; 3. Informação - mulheres entrando na era da informática; 4. Migração - mulheres, identida des e sistemas em trânsito; 5. Água - a água e a vida; e 6.Trabalho trabalho feminino entre integração e desintegração, uma comparação entre o leste, o meio e o oeste europeu.

Em função dos estudos rea liza dos com mulheres migrantes em Santa Catarina, ${ }^{2}$ integrei a área temática "Migração" e participei do grupo de trabalho "At your service Madame! Domestic servants worldwide, gender, 
${ }^{3}$ Este artigo teve como origem o trabalho apresentado no Encontro Fazendo Gênero 6: Gênero e Migração - trajetórias globais, trajetórias locais de mulheres migrantes. Florianópolis, agosto de 2004

\footnotetext{
${ }^{4}$ SASSEN, 2003, p. 41.
}

class ethnicity and profession". O meu grupo entrevistou mulheres que emigraram de países periféricos - mais especificamente peruanas, filipinas e indonésias - para trabalhar como domésticas na Europa, com o objetivo de conhecer os motivos da ida e as suas a tua is condições de trabalho. Conheci, também, uma ONG que assessora imigrantesasiátic as que trabalham na Europa e desenvolve um trabalho nos seus países de origem, em relação às princ ipa is dificulda des que envolvem a escolha de emigrar. Essa experiência me instigou a entendero que move tantas mulheres a trabalharem como domésticas na Europa, e neste artigo $^{3}$ trago uma síntese da pesquisa realizada enquanto integrante desse grupo.

\section{A feminiza ção dos fluxos migra tórios pa ra 0 trabalho doméstico}

Constata-se, nos últimos anos, um expressivo crescimento nos fluxos migratórios de mulheres em nível global, que saem de seus países de origem para trabalhar como cuidadoras, enfermeiras, assistentes de serviços domésticos ou prostitutas nos países de Primeiro Mundo, atendendo a demandas que se configuram como alternativas de geração de renda para mulheres no merca do informal. Esses processos migra tórios gera Imente são resultantes de uma complexa rede de relações decorrentes dos contextos sócio-econômicos e cultura is, tanto dos países de origem como dos países receptores. Parte dasmigrações de mulheresdos países periféric os para os países centrais é incrementada e financiada por govemos locais, processo a ltamente vantajoso na medida em que as migrantes enviam remessas signific ativas de dinheiro em moeda estrangeira para as suas famílias que permanecem no local.

Por sua vez, os países receptores, também conhecidos como países desenvolvidos, têm intensifica do essas redes transnacionais, flexibilizando as condições de trabalho para as mulheres migrantes na medida em que 0 crescente enxugamento dos benefíc ios obtidos durante o boom do Esta do de Bem-Estar So cial tem demandando toda ordem de serviços informa is, desde o trabalho doméstico a té o cuidado com idosos, doentes e crianças.

Esse s fluxos mig ra tórios que extra pola m fronteira s sã o denomina dos por Sa skia Sassen de "contrageografias da globalização" ${ }^{4}$ porque estão direta ou indiretamente associados à economia global, não se caracterizam por uma representação formal, operam com freqüência fora da lei e dos tra ta dos, e a lgumas vezes envolvem operações criminais. Esse tipo de economia desenvolveu uma infra- 
${ }^{5}$ SASSEN, 2003, p. 61.

estrutura que tem facilita do os desloca mentos a tra vés das fronteiras, propiciando os circuitos altemativos e gerando benefícios para os países ricos à custa de pessoas que estão em condições desvantajosas, entre elas um grande número de mulheres.

Evidencia-se como resulta do desses fluxos migratórios uma das faces perversas da globalização: um novo tipo de economia, parcialmente desterritorializada, que atravessa fronteiras conectando múltiplos pontos do globo, numa espécie de rede submersa, informal e ilegal, originando desregulamentação e precarização das relações de trabalho. Também as novas políticas socia is, decorrentes desse processo de globalização e aplicadas pelo Fundo Monetário Internacional, se fazem presentes nos países periféricos a tra vés dos Programas de Ajuste Estrutural, da abertura da economia para as empresas estrang eiras e da elimina ção de múltip los subsídios esta ta is, provocando, entre outros custos soc ia is, o desemprego em massa, o fechamento de empresas em setores tra dic iona is orienta dos para o merca do nacional ou local e o estímulo à monocultura para exportação, expulsando as famílias de pequenos agricultores de suas terras e atingindo, de maneira crescente, também as mulheres.

Sassen chama a atenção para a invisibilidade da dinâmica de gênero na articulação com a economia global, destacando como exemplo o lucro obtido por agenciadores a partir desses fenômenos: "quatro milhões de mulheres traficadas para a indústria do sexo e sete milhões de dólares de benefícios para as organizações crimina is". ${ }^{5}$ Por outro lado, aponta o crescente fenômeno da feminiza ção da força de trabalho nospaíses periféric os, bem como o da feminização da pobreza. Segundo dados da ONU, $70 \%$ dos pobres de todo o mundo são mulheres, que, por sua vez, têm despontado nos cenários da migração intema (nacional) e extema (intemacional) como sujeitos autônomos, em busca de melhores condições de vida para si e para seus filhos.

Migração é aqui entendida como uma ação social de cará ter ind ividual ou coletiva, espontânea ou forçada, que ocorre a tra vés de um desloca mento intemo (do campo para a cidade, de uma cidade para outra, no mesmo país), ou externo (de um país para o outro); envolve cruzamento de fronteiras a dministra tiva se polític as (territórios), e fixa ção de nova residência, bem como um processo de desenraizamento do local de origem seguido de novo enraizamento (aculturação) no local de chegada. Os motivos da migração tanto podem ter causas sócioeconômicas e políticas como também esta r associados a dimensões subjetivas. 
Os estudos sobre migração têm negligenciado as esta tístic as sobre o fluxo cresc ente de mulheres que entram anualmente no mercado de trabalho, bem como a mobilidade interna e extema das mesmas, que saem de seus locais de origem buscando melhores condições de vida ou fugindo de diferentes formas de opressão e exploração; é importante consideramos que o processo de migração para as mulheres significa, muitas vezes, a fuga de uma relação violenta ou de uma estrutura social patria rc al com ríg ida s noções do que constitui 'p rop riedade' em relação à mulher. Em geral, nos países do Terceiro Mundo as mulheres pobres não têm direito à herança e à propriedade de terras no campo, nem quando casam e muito menos quando se separam ou divorciam.

Nesse sentido, ressalto a importância de considerarmos a perspectiva de engendramento das migrações, ou seja, levar em conta que os fatores que originam e estimulam a migração de homens e mulheres são diferentes. Em função das atividades de subsistência a tribuídas em geral às mulheres, são elas as ma is pena liza das. Além disso, as mulheres mig rantes que cruzam fronteiras internacionais, em geral, ficam com a responsabilidade de prover suas famílias na pátria de origem. Esses processos transnaciona is envolvem complexas relações entre os migrantes e seus países de origem, bem como requerem a formação de novas instâncias que incluem redes sociais: de conhecidos e parentes que já estão no país para o qual querem migrar; de ONG se instituições que acolhem a s mulheres migra ntes e as encaminham; de operações econômicas de envio de dinheiro para os familiares no país de origem.

É necessá rio pontuar, ainda, que o crescente fluxo migratório de mulheres para trabalhar como domésticas em países do Primeiro Mundo é conseqüência direta do desenvolvimento desigual promovido pelo capitalismo neoliberal. Reféns da histórica dominação e exploração colonial que se perpetua a través da dominação oligárquica de suas elites, as pessoas e as famílias não conseguem sobreviver em seus países. Em função dos ajustes fisca is a tribuíd os pelo neolibera lismo a os países do Terceiro Mundo, o Esta do tem se afastado de seus compromissos, tomand ose "mínimo para o social e máximo para o capital".

\section{Mulheres migrantes - cidadãs globa is inseridas nas cadeias de assistência}

A atual fase da economia mundial tem sido ca racteriza da por desc ontinuida des e desestruturação do poder político em nível nacional. Ocorre uma 
${ }^{6}$ SASSEN, 2003, p. 67.

${ }^{7}$ SASSEN, 2003, p. 84.

${ }^{8}$ Rhacel PARRENAS, 1998.

9 Pierrete HONDAGNEU-SOTELO e Emestine AVILA, 1997. desterritorialização dos Esta dos-Nação com conseqüente diminuição da soberania e autonomia destes em relação a os parâmetros lega is sobre direitos e cidadania. Para Sassen, "o Esta do já não é mais o único lugar onde identificamos a soberania e a normatividade que dela ema na ", ${ }^{6}$ ou seja, o Esta do já nã o é ma is o sujeito exc lusivo dos direitos intema ciona is, na medida em que outros a tores como ONGs, sujeitos minoritários e organizações supranacionais estão emergindo cada vez mais como sujeitos do direito interna cional. A a utora chama a a tenção pa ra uma possível descentralização da soberania no atual contexto da globalização, uma vez que a informatização está criando nova soportunida desopera tiva se forma is pa ra a partic ipa ção de a tores e suje itos distintos do Esta do, como é o caso da participação de mulheres na elaboração e implementa ção das leis e normas do direito internacional. Obviamente, quando se refere a mulheres migrantes no circ uito internacional, a implementação crescente de um regime intemacional de direitos humanos deve se fazer presente, assinalando inclusive, conforme Sassen, "a emergência de uma sociedade civil intemacional". ${ }^{7}$

Enquanto migrantes, as mulheres deixaram seus países de origem para disponibiliza r sua força de tra balho em uma nova nação, e nesse processo surgem várias questões: como ficam seus direitos e a sua cidadania? Ocorre uma desnacionalização da cidadania ou uma ressignific ação em relação a os direitos? É possível toma rse uma cidadã global?

Aproximemo-nos das migrantes para conhecê-las melhor, saber por que elas migram e como elas chegam ao país que as contrata para trabalhar. As mulheres que trabalham como domésticas na Europa encontram-se na faixa etária de 19 a 40 anos, geralmente são procedentes de países considerados do Terceiro Mundo, muitas sossuem formação universitária e em seus países de origem não encontra ram emprego, ou consideram os salários insufic ientes para sobreviver. Conforme um estud o rea liza do por Pa rrenas com mulheres filip inas que trab a lha ra $m$ como professoras, advogadas, enfermeiras, funcionárias a dministra tiva se buroc rátic as em seu país, elas ga nhava m em média 176 dólares mensais. Fazendo um trabalho menos especializado como babás, criadas ou a companhantes, a tua Imente elas ga nham 410 dóla res em Hong Kong, 700 na Itália e 1.400 em Los Ang eles. ${ }^{8}$

Um significativo número de mulheres tem deixado seus filhos com parentes ou em instituições no país de origem para migrare trabalhar na Europa, configurando 0 que Hondagneu-Sotello e Avila definem como "matemagem transnacional", ${ }^{9}$ uma vez que essa smulheres 
deixa m seus próprios filhos nos países de origem para cuidar dos filhos de outras mulheres. É comum serem agenciadas porinstituiç ões a tra vés de pág inas na Intemet, onde figuram seus dados e habilidades acompanhados de fotos.

Os principa is motivos da emigração a ponta dos pelas mulheres são: 1) a questão sócio-econômica: falta de oportunidades de emprego ou ocupações remuneradas no país de origem, bem como a desva lorização do tra ba lho feminino; 2) o acesso à educação ou a oportunidades de maior qualificação profissional; 3) a conquista da independência econômica e social de suas famílias de origem, p rincipalmente as solteiras, viúva s ou mulheres que sofriam violência no local de origem; 4) a possibilidade de alcanç a r mobilida de social, melhorarde sta tus em relação ao emprego que exerciam nos países de origem, ou seja, serem valorizadas; 5) o acesso a serviços básicos, a tend imento à saúde; 6) experimenta rdiferentes sensa ções: conhecer um país diferente, divertir-se, ir a festas, sa ir com as a migas, a prendercoisas novas; 7) ira trás da rede fa miliar, de conhecidos ou amigos que já se encontram no país e motiva $m$ a emigração.

Muitas mulheres migrantes são a utorizadas a permanecer para exercer o trabalho de domésticas na nova pátria, mas não são reconhecidas como cidadãs; outras não recebem visto ou autorização para entrar, mas permanecem de forma clandestina e seus serviços são reconhecidos pelos patrões que as ajudam a burlaras leis. De que forma essas mulheres têm chance de serem rec onhecidas como sujeitos polític os? Qua is são, enfim, as princ ipa is dific ulda des dessas mulheres?

Os principa is problemas enfrenta dos pelas mulheres que migram para trabalhar na Europa como domésticas, segundo depoimentos colhidos, são: a falta de comprometimento por parte dos patrões em relação à regularização de papéis, documentos legais ou visto de permanência; estando ilega is no pa ís não possuem acesso aos serviços básicos, e quando adoecem não possuem plano de saúde que cubra atendimento e tratamento de doenças; o não-pagamento de horas extras; os baixos salários ou a negação de salário para mulheres que comunicam "aviso prévio"; a violência e abuso sexual por parte dos patrões; a obrigação de fazer serviços extras para a migos e parentes dos patrões; a sobrecarga de trabalho, principalmente em casas nas qua is, a lém de fazerem todos os tipos de tarefa, cuidam de crianças e idosos; a relação pessoal que se estabelece entre trabalhadoras e patrões, confundindo relações de matemalismo com relações de trabalho, o que implica falta de garantia de direitos; a 
${ }^{10}$ Arlie Russel HOCHSCILD, 2004.

${ }^{11}$ HOCHSCILD, 2004, p. 196. dificuldade de adaptação aos novos costumes, língua, clima, a limentação, etc.

A procura portrabalhadoras domésticas na Europa agenciadas por instituições tende a aumentar, sobretudo porque elas estão sendo contratadas para substituir o cuidado que a té entã o era desempenhado pelas famílias, por institutos a sila res, hospita is e outros, provocando o que Hochschild denomina de uma verdadeira "cadeia global de assistência". ${ }^{10}$ Essa s ca deias, na ma ioria das vezes, ligam três conjuntos de cuidadoras: uma mulher cuida dos filhos da migrante em casa, no país de origem; outra cuida dos filhos desta mulher que cuida dos filhos da migrante, que muitas vezes é a sua mãe ou a filha mais velha cuidando dos próprios irmãos; e a terceira na cadeia é a própria mãe migrante que deixa o seu país para cuidar dos filhos de profissiona is libera is no Primeiro Mundo. Assim, estabelece-se uma cadeia de uma ponta a outra, entre classe, raça e nações: "as mulheres mais pobres criam os filhos das ma is ricas, enqua nto mulheres a inda ma is pobres - ou ma is velhas ou ma is rura is, Ihes criam os filhos". ${ }^{11}$

A autora ta mbém chama a a tenção para o "padrão global do deslocamento do sentimento", uma vezque essas mulheres deslocam o a mor que deveriam sentir e transmitir para os seus próprios filhos para as crianças que cuidam como babás.

Esse qua dro de reestruturação no mund o do traba lho agrava-se com a diminuição do papel do Estado e recai de forma drástica sobre as mulheres, conforme Lutz: a proximadamente 10 milhões de mulheres no mundo não possuem cidada nia nos a tua is pa íses em que vivem; destas, 1 milhão são trabalhadoras domésticas e dependem da 'bondade' de seus patrões para continuar sobrevivendo no país para o qual migraram. Quase 20 milhões de mulheres no mundo vivem em condições de 'segunda categoria', lutando porsobrevivência e para terseus direitos ga rantidos. ${ }^{12}$

\section{Trabalhadoras domésticas: constituindo novas identidades e afimando diferenças}

Com a intensific ação das migrações, o problema das diferenças se intensifica. Nas grandes cidades, convivem pessoas de origens culturais, condições étnic as e soc ia is diferentes, c renças religiosas va ria das, id eologias opostasque dão origem tanto a processos de a proximação identitá ria, como de discrimina ção e exc lusão. É com essa realidade que se defronta a mulher migrante que, acostumada a viver num mundo com uma cultura 
relativamente homogênea, geralmente encontra dific uld a des para a cultura r-se.

No processo migratório das mulheres, via de regra, ocorre um fluxo predominante de certos países para outros, geralmente em função dos processos seculares de coloniza ção: as norte-africanas vão trabalhar na França, Espanha ou Itália; as peruanas, brasileiras e outra s la tinoa meric anas vão para a Espanha, Itá lia, Portugal ou Esta dos Unidos; as filipinas e indonésias são as preferidas na Alemanha, Ingla terra e Canadá; asa lbanesas, as da Eritréia ou as da Etiópia vão trabalhar na Grécia e na Itália; por sua vez, as polonesas e russas têm ido em número cada vez maior para França, Itália, Alemanha e Espanha.

Entre esses países, globalmente diferencia dos como centra is e periféricos, são construídos estereótipos que definem e caracterizam hierarquicamente as diferenças étnicas e racia is. 0 discurso e a prática da alterida de, da a ceitação do outro como diferente, com base no ra cismo e na etnia, definem, por exemplo, o modelo de "outra", ou seja, a identidade que a mulher européia considera ideal para trabalhadora doméstica. Assim, as filipinas são preferidas por sua natureza profundamente dócil e submissa, as latinas por sua disposição e força para o trabalho e as polonesas e russas por sua beleza exótica. Por sua vez, as muçulmanas, na grande maioria negras, consideradas as "outras outras" que representam a dicotomia do modelo de mulhere mãe européia, são por isso ramente agenciadas.

Esses estereótipos, que não somente negam a aceitação da multiplicidade do sujeito feminino de toda mulher real, exercem também uma grande força material em toda a sociedade. Essas imagens, todavia, não são casua is, tendo sido construídas sistema ticamente a tra vés do tempo e utiliza das por diferentes grupos com diferentes propósitos. A a bertura para a alteridade, para a a ceitação do diferente, seja do mundo urbano em relação ao migrante ou ao estrangeiro, seja deste em relação à heterogeneidade que caracteriza a vida em outros países ou na cidade, é um processo lento, dra mático e difícil.

0 reconhecimento e aceitação da alteridade, entretanto, é a condição básica para a construção da democracia, requerendo uma ética baseada no fim da intolerância e na construção da mútua a c eitação a partir

${ }^{13}$ Cf. Marcela LAGARDE, 1996, p. 11. do reconhecimento da equivalência humana. ${ }^{13}$

Dessa forma, a questão da identidade adquire um caráter político na medida em que a sociedade determina quem ela quer incluir e quem quer excluir. Atualmente, a exclusão tornou-se estrutural e o sistema admite na sua 
${ }^{14}$ Rena to ORTIZ, 2002, p. 10.

${ }^{15}$ Paula MONTEIRO, 1997, p. 62. ${ }^{16}$ Cita do por MONTEIRO, 1997, p. 63.

${ }^{17}$ Chantal MOUFFE, 2005, p. 20. lógica interna que muitas pessoas devem ficar excluídas. Por isso, nos a dverte Ortiz, "devemos estar a tentos, diversidade cultural não significa pluralidade cultural. A idéia de pluralismo contém a noção de igualdade no patamarde partic ipação e de reconhecimento dospares, enqua nto que a idéia de diversida de está a tra vessa da pela noção de hierarquia". ${ }^{14}$ É importante destacarque o direito à diferença é, necessariamente, direito a o pluralismo.

Ao migrarem de um país para outro, ou do campo para a cidade, as mulherescomeçam a tomarconsciência de suas diferenças, tanto de classe como de etnia, e passam a se confrontar com um conflito de identidade. Essa perspectiva desloca o foco da análise das diferenças cultura is de língua, religião, filiação, etc., para pensá-las do ponto de vista rela cional e político. Aqui os estudos sobre identidade étnica "se voltam para a compreensão dos modos como as pessoas se auto-atribuem as identificações". ${ }^{15}$ Éa "concepção relacionalda identida de" formula da porFredrik Barth, ${ }^{16}$ na qual a identific a çã o étnic a de um determinado grupo é o resultado da capacidade do mesmo em manter simbolicamente as fronteiras de diferencia çã o que o distinguem dos grupos vizinhos. Como toda identidade se estabelece porrelação, ela se configura no campo das identificações coletivas: a criação de um "nós" implica a "delimitação de uma fronteira e a designação de um 'eles'. Essa definição de um 'nós' geralmente tem lugar num contexto de diversidade e conflito". ${ }^{17}$

Por isso, as trabalhadoras domésticas que migram para países estrangeiros procuram as colegas da mesma terra, formam grupos de a miza de, a póiam-se e encorajamse mutuamente. As mulheres que migram experimentam, muita s vezes, uma verda deira 'a lquimia' em sua s vidas, em sua identidade e em seu cotidiano, tornando-se diferentes do que eram antes de migra rem, não sendo mais id ênticas às mulheres que perma necera $m$ em suas terras.

Como trabalhadoras domésticas, as mulheres migrantes enfrentam vários tipos de discriminação, tendo como norte uma subjetividade de classe que, imbricada com as cond ições de gênero e etnia, produz uma a lquimia na subjetividade delas. Estas, no processo conflitivo e dialético de construção de sua subjetividade, de um lado lutando contra a discriminação de gênero, classe e etnia, e de outro afirmando sua identidade de mulheres e trabalhadoras domésticas que lutam por uma causa comum, têm na va loriza çã o de sua profissã o uma conquista de a uto-estima e a utoc onfia nça e um a lic erce fundamenta I para seu processo de aculturação e emancipação. 


\section{O espaço doméstico enquanto uma relação de produção e reprodução de bens e serviços}

Os serviços de faxineira, diarista, trabalhadora doméstica ou babá têm sido uma das ocupações remuneradas mais procuradas por mulheres migrantes na medida em que essas funções exercem um papel importante na incorporação delasa o merca do de trabalho, porque a execução dessas ta refas não exige nenhuma qualificação e culturalmente é considerada um papel desempenhad o por "mulheres". Além disso, tra ba lhar como doméstica ou babá representa segurança e acolhimento para as migrantes que chegam em países desconhecidos, pois, como afima Melo, elas encontram nesse tipo de atividades "o caminho de socialização na cidade [...] o abrigo, a comida, a casa e a família". ${ }^{18}$

Ao discutir o signific ado do trabalho doméstico, o Colectivo IOÉ questiona se essa forma de intercâmbio econômico não extrapola o paradigma de mercado. A partir de uma crítica à economia neoclássica, o grupo avança na elaboração de um esquema teórico sobre as formas de intercâmbio econômico que vão além das relações mercantis e incluem as relações recíprocas e distributivas. Deixa claro que a lógica do mercado só funciona a partir da existência de determinados contextos socia is (constituciona is e normativos).

A partir dessa premissa, o coletivo propõe a mpliaro conceito de trabalho para "incluir todas as atividades dos seres humanos que constituem um esforço ou gasto de energia para satisfazer suas necessidades mediante produção de bens e serviços". ${ }^{19}$ Ressalta o viés androcêntrico de alguns a utores que insistem em designar como "traba lho" as ativida des desempenha dasna maioria por homens e como "não-trabalho" as que incluem a maioria das mulheres, evidenciando que por trás dessas definições estão presentes questões cultura is e id eológ ic as.

Trazendo para a disc ussão a multidimensionalidade do trabalho humano, o grupo considera o espaço doméstico como "um espaço de produção e reprodução dos ma is va ria dos bense serviç os, entre os qua is as múltiplas práticas de comunicação verbal, afetiva e sexual, que possuem grande importância na integração pessoal dos adultos e crianças bem como na socialização de novos cidadãos". ${ }^{20}$ Dito de outro modo, o trabalho realizado no espaço doméstico é invisibilizado porque, ocorrendo no âmbito privado, é pouco valoriza do, de baixo status social e constitui-se num mercado para migrantes indocumen- 
${ }^{21}$ Coletivo IOÉ, 2001, p. 28.

${ }^{22}$ HOCHSC HILD, 2004, p. 193. ta das. É o lugarde reprodução social no sentido de produzir e fazer circularnorma e valores sociais acerca da família, do gênero, da nacionalidade, da identidade e de outras representações sociais.

Todos sa bemos que os serviç os doméstic os em uma c asa são imprescindíveis. Ao perguntarmos como são desempenhados esses serviços, que tipo de relações se estabelecem entre as pessoas que necessitam dos serviços e quais estão dispostas a oferecê-los, o grupo afirma que essas relações podem ocorrer sob três formas: a) sob a forma de reciprocidade entre os membros da casa, que dividem as ta refas simétrica ou assimetric amente entre si; b) red istributivas, quando a cessa mos serviç os coletivos que nos são disponibilizados pelo poder público em troca do pagamento de impostos; ou c) contra ta mospessoas a tra vés de uma relação mercantil que se constitui por uma troca de trabalho entre agentesprivadosmedia da pordinheiro. ${ }^{21}$

Os serviços domésticos desempenhados pela maioria dasmulheresmigrantesna Europa seguem a lógica mercantil, ou seja, através de um contrato formal estabelece-se o valor do salário que será pago pelo contratante em troca de um determinado tipo de tarefas que serão realizadas pela pessoa contratada.

Ao indagar sobre pagamento justo, eqüidade entre países, Hochschild chama a atenção para a "mais-valia emocional"22 e constata que a assistência e o amor estão sendo distribuídos desigualmente pelo mundo. A autora indaga até que ponto os países do Primeiro Mundo não estão importando amor materno como no passado importa ram ouro, cobre, zinco e outros minérios dos países do Terceiro Mundo? Uma vez que o trabalho de tomarconta toca as emoções das pessoas, como entender a transferência de sentimento para aqueles de quem se cuida? A maioria dos patrões desconhece totalmente a vida que suas empregadas deixaram para trás, ignora que elas provêm de uma família, que algumas têm filhos, que sentem saudades, que têm sentimentos e emoções!

Pa trões e empregadas domésticas, em geral, participam de uma relação de identida de mediada pela lógica de servidão: para os patrões servir é algo natural, configurando uma relação de explora ção e iniqüida de. A servidão implíc ita no trabalho dasdomésticas faz parte de uma ideologia que crista liza essa a tivida de como ultra conserva dora em uma sociedade profundamente hierarquizada.

A função ideológica dessa ocupação trabalhadora doméstic a - baseada em rituais de diferença e maternalismo vem perpetua rum sistema de estratifica çã o social que articula nec essa ria mente asca teg oria s "g ênero", "classe" e "etnia". 
${ }^{23}$ GOFFMAN, 1999.

\section{Relações socia is estra tific adas: a linguagem e o espaço definindo as diferenças}

O emprego de doméstica implica, necessariamente, rela ção pessoal; a trabalha dora não é contra ta da somente pelo desempenho no seu serviç o, mas ta mbém pelos traços de sua personalidade que, por sua vez, são definidos pela identidade étnica. Nos países desenvolvidos, gera Imente, a exploração econômica é menos problemática do que a exploração psicológica. Esta se consolida basicamente a través de dois tipos de rituais: da diferença e do maternalismo.

Ervin Goffman define a diferença como uma espécie de cerimonial, cuja função possui um signific a do simbólico: a apreciação e a aceitação de uma pessoa deve ser transmitida regular e sistematicamente a outra (destinatária). ${ }^{23}$ Portanto, entre pessoas não igua is, é a diferença de comportamento que vai confirmar a desigualdade, pois uma posição de superiorid a de só existe em relação a outra subordinada. Nas relações entre patrões e empregados, três tipos de diferença lingüístic a são comuns: a ) a maioria das domésticas é chamada pelo primeiro nome e elas devem chamar suas patroas e patrões pelo sobrenome; b) os patrões referem-se às domésticas como "girl" ou "mädchen", moça, menina, rapariga, guria; c) os patrões apreciam (ou exigem) tratamentos diferenciados que impõem respeito: Yes, Sir...; Yes, Madam...; Sim, Senhor...; Sim, Senhora...; Sim, Madame...

Esse tipo de linguagem legitima uma lógica e carrega um signific a do colonialista, vind o a o encontro dos interesses hierárquicos que legitimam o poder. Nesse tipo de relacionamento, muitas domésticas desempenham performances para agradar suas patroas e manter um bom relacionamento.

O utro fator que caracteriza a diferença, delimitando e conferindo a inferioridade da empregada doméstica, é a divisão espacial da casa, que ocorre de várias formas: a) a iniqüidade em relação ao direito de uso do espaço para movimento e permanência doscorposna casa - "sala de visita e pisc ina não sã o luga respa ra emprega da fic a r..."; b) o controle sobre o uso do espaço da casa porparte da trabalhadora doméstica - "lugar de empregada é na cozinha"; c) o tamanho e condições do quarto de dormir da empregada na casa, que quase sempre é um cubículo sem janela e sem iluminação natural.

Outra forma de exploração muito comum é o maternalismo, que é um conceito relacionado ao papel 
da mulher como suporte intrafamiliar, de nutrir, amar e a tender às necessida des a fetivas e vitais. Em relação a o ma terna lismo, muita s pa troa s tra ta $m$ a s emprega da s como crianças, repassando roupas usadas, bijouterias, sapatos, móveis - certas de que com esse gesto estão dando presentes mas esperando em troca o a feto. Muitas patroas agem mediante chantagem emocional com as empregadas, afirmando que pertencem à família ou são sua melhor amiga, a filha que não tiveram, quando na ma ioria das vezes são elas, as patroas, que se encontram em esta do depressivo, necessitando de companhia ou de a lguém para confidenciar. Ser excessivamente matemal com a empregada confunde a relação de trabalho, que deve ser estabelecida com base nos direitos garantidos pelo contra to. Por outro lado, as trabalhadoras também devem ter chance de se emancipar, estudar, aperfeiçoarse, e a té mesmo sair de casa para divertir-se.

\section{Trabalhadoras domésticas - como sair da senidão para chegarà emancipação?}

Os movimento feministas, na súltima s déca das, têm obtido conquistas em relação à saída das mulheres do espaço privado para a esfera pública, enfatizando que o pessoal é político e mostrando que as relações de gênero são desigua is e injustas. A entra da das mulheres na esfera pública, apesar de ter levado praticamente dois séculos para se consolidar, por si só, nã o se constitui um movimento social, mas coloc ou milhões de mulheres do globo terrestre em movimento. O que me preocupa, porém, é que, no alvorecer do século XXI, mais de 100 anos depois de grandes conquistas em relação a os direitos da mulher, na passagem do capitalismo industrial para o financeiro, evidenciado pelo incremento da tecnologia, está ocorrendo um movimento contrá rio à saída prevista para a esfera públic a: 100 mil mulheres de tod o o mund o movemse a nualmente em fluxos migratórios, para assumirem trabalhos domésticos na esfera privada.

Esse fenômeno nos coloca diante de uma questão paradoxal: no auge da era da informática, com a revolução tecnológica reestrutura nd o o mundo do trabalho, como e porque se intensifica de tal maneira um mercado de trabalho informal considerado pormuitos como a rc a ic o e ocupado somente por mulheres?

A procura por empregadas domésticas na Europa tem aumentado vertig inosamente nos últimos 15 anos. A associação Network of Filipinas in Europa estima em 500 mil o número de mulheres filipinas que trabalham atualmente na Europa, e os repasses de dinheiro dessas 
${ }^{24}$ Documento elaborado pela ONG Ökumenische Asiengruppe que assessora as mulheres $\mathrm{mi}$ grantes asiáticas (ÖKUMENISC HE ASIENGRUPPE, 2000, p. 11)

25 Eleonore VON OERTZEN, 2003, p. 182.

\footnotetext{
${ }^{26}$ CAMPS, 2001.
}

mulheres para o govemo filipino somaram mais de 15 milhões de dólares entre os anos de 1982 e $1993 .{ }^{24}$

Só na Alemanha, nos anos 1990, o número de lugaresque demandaram regula mente ajuda extema para o trabalho doméstico foi de 2.650 , somados aos 1.400 trabalhos esporádicos de diaristas ou faxineiras. ${ }^{25}$ Von Oertzen polemiza a questão da divisão sexual do trabalho entre os gêneros em relação às tarefas no espaço doméstic o a o firmarque esse problema foi delegado às mulheres individualmente, quer dizer, a os casa is individualmente, ou seja, converteu-se em um problema privado. Com o avanço do neoliberalismo e as benesses do Estado de Bem-Estar Social na Europa - referência mundial no cumprimento dos direitos socia is - a oferta de serviç os públic os e coletivos tem diminuíd o dra stic a mente, tra zendo as questões do cotidiano de volta para a esfera privada e sobrecarregando de forma geral as mulheres. 0 fato de muitas mulheres terem saído para trabalhar ocupando cargos no espaço público deveria demandar um movimento circulatório de reciprocidade, de complementaridade: os homens adentrando no espaço priva do, ajudando na divisão das ta refas doméstic a s e no cuidado com os filhos. Mas não é isso que acontece: no lugar do esperado "homem novo" que divide as tarefas domésticas com a sua esposa, apareceram no cenário milhares de "novas servas".

Com o a vanço dos estudos de gênero, que entre outros tema spertinentes propõem discutira "desc onstrução" do modelo de homem cujo papel foi fixado pela sociedade patria rcal, entra em questão a divisão sexual do trabalho. Esta requer uma distribuição eqüita tiva do trabalho doméstic 0 , ou seja, requer democracia de oportunidades que subentende censo de justiça mas também envolve a ética do cuidado, que não deve ser entendida como específic a das mulheres, assim como a questão da racionalidade e da justiça não é específica dos homens!

Vic tória Camps sugere a ética do cuidado como uma proposta de eqüidade de gênero e estratégia para o enfrentamento das desigualdades, pois tra ta de mudanças na lógica pública, a tra vés da inserção de valores da esfera privada, a humanização de serviçose a complementação da ética da justiça pela ética do cuida do. ${ }^{26}$

A proposta de Camps refere-se a uma crítica à ética racional e universal centrada na defesa da liberdade e igualdade para todos, que, centrada no individualismo abstrato, elimina toda a diferença. Sugere a quebra da lógica da desumanização dos serviçose a distância que a separa dos cidadãos, a lém de evidenciar que o priva do é 
público, trazendo para este valores da lógica doméstica como proximidade e empatia.

A ética do cuidado deve ser vista como complemento da ética da justiça, porduas razões: a ética da justiça não dá conta de todosos valores morais de uma sociedade e porque é preciso revelarvalores relacionados a o espaço doméstico no espaço público.

A ética da justiça pauta-se em leis que valem para todos os cidadãos, mas é uma ética distante do indivíduo, pois não considera as particularidades de grupos específic os, que muita s vezes não estã o contempla das nas legislações. Por isso, a ética do cuidado sugere a incorporação da eqüidade, tratando diferentemente os desiguais, em decorrência de desigualdades sociais históricas, como em relação às mulheres.

Fazendo uma comparação, há 100 anos, as trabalhadoras domésticas na Europa desempenhavam praticamente as mesmas atividades que as de hoje. A principal diferença que se consta ta é que, naquele tempo, para trabalhar em casas de famílias burguesas, proc ura vam-se moças solteiras, a partir de 14 a nos de ida de nas áreas rurais, em orfanatos ou bairros de operários. Atualmente, porém, as mulheres que trabalham como domésticas na Europa possuem formação universitária, encontram nessa ocupação a melhor alternativa de geração de renda, a lgumas são casadas e deixam seus filhos nos países de origem cujos govemantes usufruem grandes vantagens com as remessas de dinheiro que entra $m$ em seus territórios a tra vés desses fluxos mig ra tórios.

Em função dessas vantagens, os países de origem nã o têm problema tiza do a questão do sig nific a tivo a umento da emigração de mulheres e pouco estímulo têm dado para que elas permaneçam em sua pátria, uma vez que não têm sido valorizadas em suas ocupações; não têm encontrado apoio nos serviços de assistência pública; enfrentam toda a sorte de problemas causados pela pobreza e exclusão social; estão sujeitas a uma sobreocupação de ta refase responsa bilida desno encargo nomeadamente com crianças, doentes, pessoas idosas, acumulando estas com tarefas produtivas e mal remuneradas.

Para que as mulheres possa $m$ realmente optar entre as a lternativas de permanecer em seus países de origem ou emigra r, são nec essária s polític a s púb lic a s volta da s pa ra elas, não somente nospaíses de onde partem mas ta mbém nos de destino. Em a mbos os lugares, tanto as mulheres como os homens devem teroportunida des de trabalho com - mesmo nível de reconhecimento e igualmente remunerado; acesso à educação gratuita e de qualidade 
para si e para seus filhos; programas voltados para a superação da violência doméstica, enfim, eqüidade de gênero. As políticas sociais, na sua grande maioria, têm sido elaboradas por homens, que não levam em consideração as reais demandas das mulheres, contribuindo em alguns contextos para a reprodução da sua subaltemidade.

O movimento de mulheres deve permaneceratento aos fluxos migratórios de mulheres desencadeados pelo processo de globalização da assistência e continuar incentivando a luta por eqüidade de gênero nas políticas públic as que levem em conta a emancipação das mulheres no sentido de tirá-las da cond ição de serva s e tra nsformá las em sujeitos polític os.

\section{Referências bibliográfic as}

CAMPS, Vic toria. O século das mulheres. Lisboa: Editorial Presença, 2001

COLETIVO IOÉ. Mujer, inmigra ción y trabajo. Madri: IMSERSO - Ministério de Trabajo y Assuntos Sociales, 2001.

GOFFMAN, Ervin. Manicômios, prisões e conventos. 6. ed. São Paulo: Perspectiva, 1999.

HOC HSC HILD, Arlie Russel. "As c a deia s g loba is de assistência e a mais-valia emocional". In: HUTTON, Will; GIDDENS, Anthony. No limite da racionalidade - convivendo com o capitalismo global. Rio de Janeiro: Record, 2004. p. 187-209.

HONDAGNEU-SOTELO, Pierrete, a nd AVILA Ernestine. "'Im here, but I'm there'. The Meanings of Latina Transnational Motherhood." Gender and Society, v. 11, n. 5, 1997. p. 548-571.

LAGARDE, Marcela. Género y feminismo - desarrollo humano y democracia. Madrid: Horas \& Horas, 1996.

LSBOA, Teresa Kleba. Gênero, classe e etnia - trajetórias de mulheres migrantes. Florianópolis: Editora da UFSC; Chapecó: Argos, 2003.

LUTZ, Helma. Geschecht, Ethnizität, Profession - Die neue Dienstmädchenfrage in Zeitalter de Globalisierung. Münster: Iks - QuerFormat, März 2000.

MELO, Hildete P. "De criadas a trabalhadoras". Revista Estudos Feministas, Rio de J a neiro: IFC S/UFRJ , v. 6, n. 2, p. 323-357, 1998.

MONTEIRO, Pa ula. "G loba liza ção, id entida de e diferença". Novos Estud os CEBRAP, n. 49, p. 47-64, nov. 1997.

MOUFFE, Chantal. "Por um modelo agonístico de democracia". Revista Sociologia Política, Curitiba, n. 25, p. 11-23, nov. 2005. 
ORTIZ, Rena to. "Choque de civiliza ções?" Nuevamerica, Rio de Janeiro, n. 96, p. 4-17, dez. 2002.

ÖKUMENISC HE ASIENGRUPPE e.V. Die unsic htbare "Perlen" migrantinnen im informellen Arbeitsma rkt. Frankfurt, Ma i 2000.

PARRENAS, Rhacel. The Global Servants: Migrant Filipina Domestic Workers in Rome and Los Angeles. Palo Alto, California: Stand ford University Press, 1998.

SASSEN, Sa skia. Contrageografias de la globalización gênero e cidadania nos circuitos fronteiriços. Madri: Trafic antes de Sueños, 2003.

VON OERTENN, Eleonore. "Cada mujer en su lugar - la nueva división intemacional del trabajo em la reprodución doméstica". In: MEENTZEN, Ângela; GOMÁRIZ, Enrique (Orgs.). Democracia de gênero, uma propuesta inclusiva. El Salva dor: Funda ción Heinrich Böll, 2003. p. 181-197.

[Recebido em agosto de 2006 e aceito para publicação em agosto de 2007]

\section{Migratory Flows of Women for Reproductive Work: The Globalization of Assistance}

Abstract: Based on an experience as a member of the group that worked with the theme of migration of women at the Internationa le Fra uen Universität (IFU) in 2000, this artic le presents a discussion about the migratory flows of women who work as domestic servants. There is a true globalization of assistance in this process, which even establishes chains between women of different nations, classes and ethnicities. The main causes of the migrations are linked to the strugg le for survival and the opportunity to work, study and a chieve independence from violence and oppression. I propose that, to conta in migratory flows, public policies that meet the basic needs of the women in their countries of orig in are nec essary.

Key Words: Female Migration; Globalization of Assistance; Gender Equity; Public Polic ies for Women. 